\title{
Study on SunYat-sen's Thoughts of Human Resource Management Ziwei Peng ${ }^{1, a}$, Shuang Peng ${ }^{1, b^{*}}$ \\ ${ }^{1}$ Business School, China West Normal University, Nanchong 637009, China apengzw1996@126.com, bjf1970@126.com \\ ${ }^{*}$ The corresponding author
}

\begin{abstract}
This paper analyzes the human resource management thought of Mr. SunYat-sen from the aspects of selection, education, employment and encouragement. In the selection, Sun Yat-sen advocates using examination and election methods to select talent, adhering to taking both ability and political integrity as talent selection criteria. In education, Sun Yat-sen advocates focusing on improving the quality of people, implementing the education for all and compulsory education, using multi-channel to train people. In the employment aspect, he advocates "make the best use of people and talent", adheres to "use the sagacious person", advocates abolition of life-long system and oppose "reward contribution with official post"; in encouraging people, he advocates giving create inventors high rewards, stimulating talents with fat salary, strengthening supervision and inspiring people with cause. In practice, he set an example, inspired the world.
\end{abstract}

Keywords: Human resource management; Talent selection; Talent education; Use of talent; Motivation of talent

\section{孙中山人力资源管理思想研究}

\author{
彭紫微 ${ }^{1}$, 彭双 ${ }^{1}$ \\ （西华师范大学商学院，四川 南充）
}

摘要: 从选人、育人、用人和励人的角度分析了中山先生的人力资源管理管理思想。在选人方面, 孙中山主张以考试和 选举的方式选拔人才, 主张坚持德才兼备的人才选拔标准。在育人方面, 孙中山主张注重提高国民素质, 主张实施全民教育 和义务教育，主张多渠道培养人才。在用人方面主张 “人尽其才，才尽其用”，坚持 “用人唯贤”，主张废除终身制，反对 “以 官赏功”; 在励人方面，主张重奖创造发明者、高薪激励人才、加强监督、以事业励人，在实践中他以身作则，感召天下。

关键词: 人力资源管理; 选人; 育人; 用人; 励人

中图分类号: C933. 2 文献标志码: A

\section{引言}

伟大的革命先行者孙中山先生, 在其领导中国民主主义革命过程中, 形成了完整、系统的人力资源管 理思想, 他在选人、用人、育人和励人等方面都有精湛独到的主张, 至今对我国现代化建设事业还有极大 的参考价值。

\section{1 选人}

\section{1 主张以考试和选举结合的方式择人}

孙中山研究了古今选才用人的制度，总结了中国历代选才用人的经验教训，考察并借鉴了西方诸国选 才用人的利弊优劣, 主张以考试和选举结合的方式选拔人才。“仅有选举不能辨别一个人的才能高低, 仅 有考试也不能识别一个人贤与不贤。只有将考试和选举结合起来, 通过考试辨其才; 由选举判断其品德。 
这样才能挑选出德才兼备的合格人才。” ${ }^{[1]}$ 他在纪念《民报》创刊一周年的演讲中提出, 革命胜利建立起 共和制度后, 就要改革人才选拔制度, 扬古今中西之长, 避其所短, “要设立独立机关, 专掌考选权, 大 小官吏必须考试, 定了他的资格。无论那官吏是选举的抑或委任的, 必须合格之人, 方得有效。” ${ }^{[2]}$ 他在 《五权宪法》中说: “没有考试, 虽有奇才之士, 具有飞天的本领, 我们亦无法可以晓得, 正不知天下埋 没了多少人才。” 他坚持自己的用人方略: “以后国家的用人行政, 凡是我们的公仆, 都要经过考试, 不能 随便乱用的。”

总起来说, 孙中山完成了从科举考试到文官考试的对接, 奠定了我国近代文官考试制度的基础。这些 方法的实行, 既避免了科举制 “以文为万能” “、唯文是务” 的弊端, 又弥补了西方仅凭一张利嘴竞选而 又无真才实学的不足。

\section{2 主张考试权独立}

考试权要独立。这是孙中山在其《五权宪法》政体模式中设计的一种政治思想, 构成了《五权宪法》 的主要内容和基本特征之一。诚如 1906 年他与该鲁学尼等人谈话中所说: “希望在中国实施的共和政治, 是除立法、司法、行政三权外还有考试权和纠察权的五权分立的共和政治。” ${ }^{[5]}$

\section{3 选才标准}

首先, 孙中山非常重视人才的道德水准。在选拔政府官员的标准时, 孙中山提出了 “国民公仆” 的道 德品质标准: 一是应 “一心一意为国来奋斗”, “一生一世不存升官发财的心理, 只知道作救国救民的事业”; 二是不应享有特权, 在政治上、经济上与国民平等; 三是应严格约束自己, 时刻意识到自己是为人民办事 的; 四是应能官能民, 而不应把做官当成终身职业, “朝作总统, 夕可解职; 朝为军长, 夕可归田”。 ${ }^{66]}$

其次, 孙中山主张选择那些德才兼备的人才。孙中山明确提出, 选拔使用人才, “当议员或作官吏的 人, 必定要有才有德, 或有什么能干, 若是没有才没有德, 又没有什么能干, 单靠有钱是不行的。” ${ }^{[7]}$ 他 在任南京临时政府大总统期间, 就公开宣布了自己选取任使官吏的基本原则: “任官授职, 必赖贤能。” 他 在批转内务部《请颁文官试验令》的呈文时说: “国家建官位事, 惟任贤选能, 乃禁厥职。古今中外, 目 越斯旨。” 在南京临时政府成立时, 百废待兴, 人才缺乏。针对这种情况, 孙中山特意指示内务部慎重用 人, 提出 “务当悉心考察、慎重铨选, 勿使非才滥等、贤能远引, 是为至要”。 ${ }^{[8]}$

最后, 坚持选拔那些具有坚强意志的人才。孙中山在领导资产阶级民主革命的过程中, 可以说是历尽 艰辛。辛亥革命前, 武装起义经历多次失败, 革命事业也经历了多次低潮。革命事业的现实, 需要革命党 人具备坚定的信念和意志。推翻清王朝的统治后, 革命党原来的内部政见分歧愈演愈烈, 甚至派别林立。 孙中山注意到, 革命力量内部有一些缺乏革命意志的投机分子。因此, 在选择和使用人才时, 他特别强调 被选拔者要具备坚定的革命意志。早在辛亥革命发生以前的 1909 年, 他在给吴稚辉的信中就谈到革命事 业所面临的内外困难, 并特别推崇那些革命意志坚定的人。他说; “际此胡氛黑暗, 党有内哄, 诚为至艰 危困苦之时代, 即为吾人当努力进取之时代也。倘有少数人毅力不屈, 奋勇向前, 支撑得过厄运, 则以后 必有反动之佳境来也。” 1923 年, 他电召叶恭绰回国, 在对叶的谈话中, 我们可以看到当时他所面临的内 部问题及其用人观的这一变化: “我内部干部, 派别分歧, 政策之执行, 固不能贯彻。即行政事务, 亦互 相牵掣, 各为其私, 其何以济? 君既意志坚决, 我想将一切政务事务, 交君主持, 我专务其大者远者何如?” $[9][10]$ 


\section{2 育人}

\section{1 注重提高国民素质}

中山先生清楚地认识到一国的国民程度、国民素质状态与该国政治、经济、文化等的发展密切相关, 深刻地认识到国民素质对建设、维护共和政体的重要作用。他清楚地认识到国家的根基是建筑在国人思想 之上, 他清醒地知道: “国家之兴亡, 政策之隆污, 系乎人心之振糜。” 又说: “夫国者, 人之所积也。人 者, 心之所器也。国家政治者, 一人群心理之现象也。是以建国之基, 当发端于心理。” [11]

中山先生把树立爱国主义，提高人的政治素质放在改造和提高国民素质的首位。他说: “做人的最大 事情是什么呢? 就是要知道怎么样爱国, 怎么样可以管理国事”, “国民须人人有爱国心”, “若我国四万万 人, 以爱身爱家之思想之能力, 合而爱国, 则我国之富强, 对内对外, 可以在地球上占第一强国。” “爱 国心重者, 其国必强, 反是则弱。” ${ }^{[12]}$ 反复强调了爱国是做人的基本准则, 是国家富强的前提。

中山先生非常重视国民文化素质的提升。他认为西方列强国力强盛是由于文化科学技术的发达, “其 国多士人”; “故欲我国转弱为强, 反弱为盛, 必俟学校振兴, 家弦户诵, 无民非士, 无士非民, 而后可与 泰西诸国并驾齐驱, 驰骋于地球之上。” 他把普及教育, 提高国民文化素质看作是建设近代化国家的重要 条件, 主张在工业化建设实践中解决培养科技人才和提高文化科学水平的问题。他说: “建设事业, 必须 学问。”又说: “中国富强事业, 非先从事普及教育, 使全国人民皆有科学知识不可。” ${ }^{[13]}$

中山先生也重视提高国民的道德素质。孙中山认为: “要维护民族和国家的长久地位, 还有道德问题, 有了很好的道德, 国家才能长治久安。”

\section{2 多种渠道培养人才}

中山先生提出了三种培养人才的途径:

一是 “多开学堂”, 以培养新式人才。“今天下之失教亦已久矣, 古之库序无闻焉, 综人数而核之, 不识丁者十有七八, 妇女识字者百中无一。此人才安得不乏, 风俗安得不颓, 国家安得不弱? 此所谓天生 之材自安于弱, 虽多置铁甲、广购军装, 亦莫能强也! 必也多设学校, 使天下无不学之人, 无不学之地。 则智者不致失学而嬉, 而愚者亦赖学以知理, 不致流于颓悍, 妇孺亦皆晓诗书。如是, 则人才安得不盛, 风俗安得不良, 国家安得而不强哉!” 1903 年他在日本东京创办青山军事学校, 以培养革命军事人才。孙 中山还在日本创建了中国最早的航空学校, 即 “中华革命党近江八日市飞行学校”。1914 年, 孙中山在东 京设立政法学校, 以培养政法干部。1924 年, 他在共产国际的帮助下, 创办了著名的黄埔军官学校, 为建 立一支新型的革命武装队伍培养了大批军事骨干。

二是 “多派留学生到各国之科学专门校肄业”。在南京临时政府财政十分困难的情况下, 孙中山还派 留学生出国深造, 鼓励学生到美、法等国勤工俭学。毕业后再入各种工厂练习数年则能够经营实业。

三是利用外籍引进的人才培养华人。

\section{3 主张实施全民教育和义务教育}

他在《致郑藻如书》中倡导 “多设学校, 使天下无不学之人, 无不学之地”, 要努力实现 “人无贵贱 皆奋于学” 的目标。他还主张实行义务教育 “多办义学, 让一般没有钱的人都可以去读书。” ${ }^{[15]}$

中山先生尤其主张提高妇女地位、注重女子教育: “提女子教育为最为重要之事。” 主张对女子进行专 
门教育, 倡导开办女校, 培养妇女人才。他在广东女子师范十七周年校庆纪念会上讲话中指出 “: 我国有 四万万人, 一半是男人, 一半是女人。……所以我们革命之后, 要实行男女平权。广东的省议会, 要有女 议员。女人能够和男人一样做议员，与闻国家大事。” ${ }^{[16]}$

\section{3 用人}

\section{1 人尽其才, 才尽其用}

孙中山 1894 的《上李鸿章书》中就指出: “其用人也, 务取其所长而久其职。故为文官者, 其途必由 仕学院, 为武官者, 其途必由武学堂, 若其他, 文学洣博者为士师, 农学熟悉者为农长, 工程达练者为监 工, 商情谙习者为商董, 皆就少年所学而任其职。总之, 凡学堂课此一业, 则国家有此一官, 幼而学者即 壮之所行, 其学而优者则能仕。” “人既尽其才, 则百事俱举; 百事举矣, 则富强不足谋也 $\left.{ }^{[17]}\right)$ 。在长期的 革命斗争中, 孙中山就是根据各人的优长来安排工作, 如军事方面主要依靠黄兴、陈其美、李烈钧、许崇 智、蒋介石等人, 政治方面主要倚重宋教仁、胡汉民、汪精卫等, 理论宣传工作由陈天华、章太炎、朱执 信、戴季陶等担任, 财政方面常常由邓泽如、廖仲恺等负责。

\section{2 用人唯贤}

孙中山襟怀坦白, 不记私怨, 对那些与自己政见不合的人, 甚至是反对自己、背叛过自己的人, 只要 能转变立场, 仍一如既住, 给以信赖, 量才擢用。他在《复温树德函》中曾说: “荷忠于文之主义, 虽仇 可友。” 如杨坤如、李云复等 “皆尝围攻公府, 谋贼吾命, 文犹许其自新, 任之不疑”。他还宣布: “除背 叛民国罪在不赦外, 其余附合北方伪政府之人, 凡愿自拔来归, 有悔过之诚者, 悉于宽免。其有一长足录, 苟操守可信, 均可量予录用。”

同时，孙中山针对当时中国资金少、技术落后、人才缺乏的具体情况，提出了利用国外人才为国内服 务, 并认为利用外国人才是发展中国实业的捷径, 是 “兴国之要图” “、救亡之急务”。他说: “凡是我们 中国应兴事业, 我们无资本, 即借外国资本; 我们无人才, 即用外国人才” “利用外资, 利用外才, 以图 中国之富强。” 我们之所以要这样, 就是要取人之长, 补己之短, 这样, “十年之内, 我国之大事业必能林 立于国中, 我实业之人才亦同时并起。十年之后, 则外资可以陆续偿还，人才可以陆续成就，则我可以独 立经营矣。” ${ }^{[18]}$ 孙中山在《孙文学说》中说: “欢迎列国之雄厚资本, 博大规模, 宿学人才, 精练技术, 为我筹划, 为我组织, 为我经营, 为我训练, 则十年之内, 我国之大事业必能林立于国中, 我实业之人才 亦同时并起。十年之后, 则外资可以陆续偿还, 人才可以陆续成就, 则我可以独立经营矣”。孙中山认为 中国需要两种类型的外籍人才: 一是军事人才, 帮助中国训练军队。二是实业人才, 以帮助中国发展实业。 而实业人才中最急需的则是发展交通运输、商业、农矿事业的外籍专门人才。在引进人才的来源问题上, 孙中山没有特别偏好, 只要有真实本领, 无论来自何国都持欢迎态度。在引进人才途径上, 孙中山主要论 述了三种: 一是托外国友好人士代聘。如: 委托美国商人戴德律、咸马里将军夫人等物色、代聘工程技术 专家、经营管理百货公司专家等。二是由外国借款公司推荐。如: 1923 年 4 月签订的《广州成都金币借款 合同》规定: “一俟提供此项借款, 即由政府与受托人协同推荐, 并由政府委任一有名望之加拿大或英国 顾问工程师公司与督办协同办理此路事务。其驻中国代表应是加拿大人或英国人，应是建造期内总工程 师”。三是请外国组织或政府选派。由于孙中山一直未能掌握全国政权, 无法指挥中国驻外公使, 以致近 代中国引进人才的主要途径———中国驻外使馆不能帮助孙中山引进人才。 ${ }^{[19]}$ 


\section{3 反对 “以官赏功”}

在人才的使用上, 孙中山根据中国的具体国情和传统封建人才制度的弊端, 提出在任人上要反对 “以 官赏功”。武昌起义胜利后, 革命队伍中的一些人认为, 如果一个人为国家为革命做出了贡献, 国家理应 给予相应的官职做回报, 还有人提议对那些为革命献身的烈士的子弟给予照顾。孙中山认为这种做法应当 禁止。他认为当官必须有真才实学, 而对其取得的功劳或贡献则可以采取优恤、授勋、奖励等方式作为回 报。[20]

\section{4 废除终身制}

孙中山主张能上能下, 能官能民, “朝做总统, 夕可解职; 朝为军长, 夕可归田”, ${ }^{[21]}$ 废除官位终身制。 孙中山还以身作则，在南北议和之时，毫不犹豫地卸去民国临时大总统一职。

\section{4 励人思想}

\section{1 重奖创造发明者}

孙中山主张重奖创造发明者。他认为, 要想使国家振兴, 迅速发展中国经济, 发展中国的各项社会事 业, 使中华民族快速崛起, 就必须鼓励发明创造, 用重奖的方法去激励人们搞创造发明。他说: “虽一才 一艺之微, 而国家必宠科名。” “学者倘穷一新理, 创一新器, 必邀国家之上赏”。他想以此达到激励人 才、造就人才的目的, “是故, 人能为奋, 士不虚生”。辛亥革命时期, 孙中山就下令奖励翻译和介绍西方 各种新思想的知识分子, 以表彰他们的贡献。对于那些办实业有成绩的企业家, 他为之题写徧名和赞词, 以示关怀和表彰。他还说, 国家建设一定要依靠专门家, 只要他们有本领, 忠心为国家做事, 就应当把国 家大事放手交付给他们, 要尊重、信任专门家, 调动专门家的积极性, 而不能处处设卡, 限制专门家, 使 其主观能动性发挥不出来。

\section{2 高薪激励}

孙中山主张 “厚其养廉, 永其俸禄”。给予优厚俸禄, 改善官员门的生活与工作条件, 使他们 “无瞻 顾之心而能专一其志”, 使之专心致志地工作, 激发人才的积极性和创造性。

\section{3 加强监督}

孙中山主张加强对政府官吏的监督。他强调给予人民以选举权、罢免权、创制权、否决权来管理政府, 还主张建立监督官员的专门机构对政府官吏进行监督, 要求集中外之精华, 防止一切流弊, “便要采用外 国的行政权、立法权、司法权加入中国的监察权”，这样，“对于政府之中的一切官吏，一面可以放出来， 又一面可以调回来，来去都可以从人民的自由”。

\section{4 以事业励人}

孙中山一生向往大同世界, 而 “天下为公” 则是大同世界思想的核心。他认为, “天下者, 是天下人 之天下”, 革命的目的, 就是要使 “人人平等幸福”。为达此目的, 孙中山以改造天下为己任, 主张通过平 均地权，节制资本，实现经济平等；通过 “三民主义” 达到 “民有、民治、民享”, 实现政治平等。建立 平等、自由而富强的中国激励了无数仁人志士为之奋斗甚至献身。

\section{5 以身作则, 感召天下}

孙中山勤政为民, 廉洁奉公, 一生 “尽瘁国事, 不治家产”。 ${ }^{[22]}$ 他在任临时大总统期间, 办公场所和 
居住条件都十分简婳; 北洋军阀提出给予他总统 “厚禄”, 遭到他的拒绝。他说: “他人出血汗犹未得偿, 我能腼颜独被优异耶?” [23] [4] (P409) 他宽以待人，不计夙怨。他认为只要忠于三民主义，“虽仇可友”; “除背叛民国罪不在赦外，其余附合北方伪政府之人，凡愿自拔来归，有悔过之诚者，悉予宽免，'; “其 有一长足录, 荷操守可信, 均可量予录用。” ${ }^{[24]}$ 如此胸襟和器量, 连他的政敌也极为叹服。 ${ }^{[25]}$

\section{参考文献:}

[1]郑淑芬．简论孙中山考试权、监察权独立的思想 $[J] ，$ 中国青年政治学院学报，2000 (12)：50

[2] 孙中山．孙中山选集（全一册）[C]，北京：人民出版社，1981：88．

[3] 孙中山．孙中山全集 (第 5 卷) [C]，北京：中华书局，1981：494。 .

[4] 耿相鬼. . 论孙中山的人才思想 $[J]$. 浙江海洋学院学报 (人文科学版)，2009，(2)：56-61.

[5]孙中山, 与该鲁学尼等的谈话, 孙中山全集第 1 卷 [C], 北京：中华书局，1981：319-320. .

[6] 蔡玉高, 李菲。南京临时政府遗存珍档揭秘：孙中山签”慎重用人”令 [OL], http : //news. xinhuanet.com/politics/2011-10/06/c_122123203.htm

[7]张否．孙中山思想研究 [M]，北京：中华书局，1981.

[8]许海芸. 孙中山构想建立新型文官制 [N]. 中国档案报, 2016-03-11 (001).

[9] 孙中山. 与叶恭绰的谈话 (1923 年 5 月 17 日), 孙中山集外集补编 [M]，上海：上海人民出版社, 1994 .

[10]杨树标，董建波. 论孙中山的用人观 $[J]$. 历史教学问题，2003，(1)：15-18，27.

[11] 孙中山．孙中山全集 (第 6 卷)，北京：中华书局，1981：158-159。

[12] 孙中山. 孙中山全集 (第 6 卷)，北京：中华书局，1981：23。

[13]孙中山．孙中山全集 (第 10 卷)，北京：中华书局，1981：19

[14] 谢超峰. 试论孙中山的人才观 $[J]$. 淮北煤炭师范学院学报(哲学社会科学版), 2007, (3)：114-118.

[15]胡汉民编， 《总理全集》第 2 集，上海：上海民智书局, 1930： 234.

[16] 耿相魁. . 论孙中山的人才思想 $[J]$. 浙江海洋学院学报 (人文科学版), 2009, (2) : 56-61.

[17]孙中山．孙中山全集(第六卷)．北京：中华书局，1984：192

[18] 耿相鬼, 。论孙中山的人才思想 $[J]$. 浙江海洋学院学报 (人文科学版), 2009, (2)：56-61.

[19]柳卫东. 略论孙中山的引进人才思想 [J]. 浙江学刊, 2004(2)： 198-200.

[20]柏杨. 孙中山人才思想研究 [D]. 吉林大学, 2007

[21]孙中山．孙中山选集（全一册）, 北京：人民出版社，1981： 101 .

[22]耿相魁, 。论孙中山的人才思想 $[J]$. 浙江海洋学院学报 (人文科学版), 2009, (2): 56-61.

[23]孙中山全集: 第 3 卷 [M]. 北京: 中华书局，1984：409.

[24]孙中山全集: 第 5 卷 [M]. 北京: 中华书局, 1985: 615 .

[25] 谢超峰. 试论孙中山的人才观 $[J]$. 淮北煤炭师范学院学报 (哲学社会科学版), 2007, (3)：114-118.

\section{References:}

[1] Zheng Shufen. On Sun Yat-sen's Independent Idea of the Right of Examination and Supervision [J], China Youth College of Politics, 2000 (12): 50

[2] Sun Yat-sen. Sun Yat-sen Anthology (one volume) [C], Beijing: People's Publishing House, 1981: 88.

[3] Sun Yat-sen. Sun Yat-sen Complete Works (Volume 5) [C], Beijing: Zhonghua Book Company, 1981: 494.

[4] Geng Xiangkui. On Sun Yat-sen's Thought of Talents [J]. Journal of Zhejiang Ocean University (Humanities Sciences), 2009, (2): 56-61. 
[5] Sun Yat-sen, Conversation with Lu Xueni and Others, Sun Yat-sen Complete Works Volume 1 [C], Beijing: Zhonghua Book Company, 1981: 319-320.

[6] Cai Yu Gao, Li Fei. Uncovering Secret of Nanjing Temporary Government Remained Precious Files: Sun Yat-sen Signing the Decree of "Prudent Appointment" [OL], http://news.xinhuanet.com/politics/2011-10/06/c_122123203.htm

[7] Zhang Lei. Study on Sun Yat-sen Thought [M], Beijing: Zhonghua Book Company, 1981.

[8] Xu Haiyun. Sun Yat-sen Conceiving of the Establishment of a New Civil Service System [N]. China Archives, 2016-03-11 (001).

[9] Sun Yat-sen. Talk to Ye Gongchao (May 17, 1923), Sun Yat-sen Collection Supplement [M], Shanghai: Shanghai People's Publishing House, 1994.

[10] Yang Shubiao, Dong Jianbo. On Sun Yat-sen's Personnel Strategy [J]. Issues of History Teaching, 2003, (1): 15-18, 27.

[11]Sun Yat-sen. Sun Yat-sen Complete Works (Volume 6), Beijing: Zhonghua Book Company, 1981: 158-159.

[12] Sun Yat-sen. Sun Yat-sen Complete Works (Volume 6), Beijing: Zhonghua Book Company, 1981: 23

[13] Sun Yat-sen. Sun Yat-sen Complete Works (Volume 10), Beijing: Zhonghua Book Company, 1981: 19

[14]Xie Chaofeng. On the View of Talents of Sun Yat-sen [J]. Journal of Huaibei Coal Teachers College (Philosophy and Social Sciences Edition), 2007, (3): 114-118

[15]Hu Hanmin. Complete Works of the Prime Minister" $2^{\text {nd }}$ Volume, Shanghai: Shanghai Minzhi Press, 1930: 234.

[16]Geng Xiangkui. On Sun Yat-sen's Thought of Talents [J]. Journal of Zhejiang Ocean University (Humanities Sciences), 2009, (2): 56-61.

[17]Sun Yat-sen. Sun Yat-sen Complete Works (Volume 6). Beijing: Zhonghua Book Company, 1984: 192

[18]Geng Xiangkui. On Sun Yat-sen's Thought of Talents [J]. Journal of Zhejiang Ocean University (Humanities Sciences), 2009, (2): 56-61.

[19]Liu Weidong. On Sun Yat-sen's Thought of Introducing Talents [J]. Journal of Zhejiang University, 2004 (2): 198-200.

[20]Bai Yang. Sun Yat-sen's Thought of Talent [D]. Jilin University, 2007

[21]Sun Yat-sen. Sun Yat-sen Selected Works (all one book), Beijing: People's Publishing House, 1981: 101.

[22]Geng Xiangkui. On Sun Yat-sen's Thought of Talents [J]. Journal of Zhejiang Ocean University (Humanities Sciences), 2009, (2): 56-61.

[23] Sun Yat-sen Complete Works: Volume 3 [M]. Beijing: Zhonghua Book Company, 1984: 409.

[24] Sun Yat-sen Complete Works: Volume 5 [M]. Beijing: Zhonghua Book Company, 1985: 615

[25]Xie Chaofeng. On the View of Talents of Sun Yat-sen [J]. Journal of Huaibei Coal Teachers College (Philosophy and Social Sciences Edition), 2007, (3): 114-118 